\title{
Antioxidant Activity and Assessment of Total Phenolic and Flavonoid Contents of Caesalpinia pulcherrima leaf Extract and Fractions
}

\author{
A. Ighodaro ${ }^{1 *}$ and O.K Ogbeide ${ }^{2}$ \\ ${ }^{1}$ Quality Control and Research Department, Edo Pharmaceuticals Ltd, Benin City, Edo State, Nigeria. \\ ${ }^{2}$ Department of Chemistry, Faculty of Physical Sciences, University of Benin, Benin City, Edo State, Nigeria. \\ Corresponding Author's email: nobleighos@yahoo.com Tel.: +2348039210070 \\ Received 22 June 2020; accepted 10 July 2020, published online 28 August 2020
}

\begin{abstract}
Oxidative stress has been shown to play an important role in the development of many diseases. Indeed, the increase in total antioxidant status is imperative in the recuperation from these diseases. The antioxidant activity, total phenolic and flavonoid contents of Caesalpinia pulcherrima leaves were determined in this study. The powdered dried leaves of C. pulcherrima were screened for their effect on 2,2-diphenyl-1-picrylhydrazyl radical (DPPH). Total phenolic and flavonoid contents of the extract and fractions were estimated using established methods. Concentrations of the plant extracts required for 50\% inhibition of DPPH radical scavenging effect $\left(\mathrm{IC}_{50}\right)$ were recorded as 3.20, 48.11, 33.12, 9.15, 27.26, 17.90, 272.18 and $55.51 \mu \mathrm{g} / \mathrm{ml}$ for Ascorbic acid, $100 \% \mathrm{n}-$ hexane, $50 \%$ n-hexane: $50 \%$ ethyl acetate, $100 \%$ ethyl acetate, $50 \%$ ethyl acetate:50\% methanol, 100\% methanol, 90\% methanol:10\% water fractions and crude extract, respectively. Total phenolic and flavonoid contents were highest for $100 \%$ ethyl acetate fraction. The leaf extract and fractions of C. pulcherrima exhibited notable radical scavenging activity and therefore corroborate its use as a natural plant antioxidant by preventing free radical damage.
\end{abstract}

Keywords: Caesalpinia pulcherrima, total phenolics, total flavonoids, antioxidant activity

\section{INTRODUCTION}

Therapeutic plants have been used as longestablished treatments for numerous human diseases for many decades [1]. The medicinal attribute of different plants is due to the active phytochemicals present in different parts of the plant [2]. Medicinal plants continue to be an important therapeutic aid for the sicknesses of man. The search for divine health, long-life and for remedies to relieve pain and discomfort drove early man for the exploration of his immediate surroundings and resulted in the use of many plants, animal products, and minerals, etc. and the development of a variety of therapeutic agents. Today, there is a renewed interest in traditional medicine and an increasing demand for more drugs from plant sources. This revival of interest in plantderived drugs is mainly due to the current widespread belief that "greenmedicine" is safe and more dependable than the costly synthetic drugs, many of which have adverse side effects. Nature has bestowed upon us a very rich botanicals and a large number of diverse types of plants grow wild in different parts of our country.

Free radicals such as reactive oxygen and reactive nitrogen species (ROS and RNS) are usually generated during cellular metabolism and by exogenous means [3]. Apart from their importance in maintaining the redox status, cellular signalling and immune adjustment [4], they are well known for their detrimental effects on cellular biomolecules such as DNA destruction, tissue wound, protein mortification [5,6]. Antioxidants aid in destroying these free radicals as well as the oxidative reactions they initiate thereby preventing cell destruction which may occur because of these oxidative reactions [3]. Plants represent a wealthy basis of natural antioxidant that can be used to avoid these oxidative mutilations [7].

Caesalpinia pulcherrima is a species of flowering plant in the pea family; Fabaceae that is native to the tropics and subtropics of America. There are various medicinal importance of $C$. pulcherrima based on its different parts such as treatment of fever, jaundice, malaria and gastrointestinal disorders. It has also been found to possess antioxidant, antiinflammatory and analgesic properties as well as prevention of chronic rheumatic disorder $[8,9]$. Many compounds have been isolated from different parts of the plant, including pulcherrin $\mathrm{A}$, pulcherrin $\mathrm{B}$, pulcherrimin $\mathrm{A}$, pulcherrimin $\mathrm{B}$, pulcherrimin $\mathrm{C}$ and many other cassane-type diterpenoids [10]. 


\section{MATERIALS AND METHODS}

\section{Collection and preparation of plant materials}

The fresh leaves of $C$. pulcherrima were collected in University of Benin, Benin City. The plant sample was authenticated at the Forestry Research Institute of Nigeria (FRIN), Ibadan with UCC voucher specimen number FHI 109969

\section{Extraction of Plant Sample}

Five Hundred gramms $(500 \mathrm{~g})$ of the leaves of $C$. pulcherrima were macerated in 3 litres of methanol for four days. The extract was filtered using Whatman's (No. 1) filter paper and the filtrate concentrated to dryness in vacuum at $40^{\circ} \mathrm{C}$ using rotary evaporator. VLC was employed for the fractionation of the extract.

\section{Estimation of antioxidant activity}

The scavenging effect of the crude methanol extract of $C$. pulcherrimaleaf on DPPH radical was determined using the method described by Kim et al. [11]. A solution of $0.1 \mathrm{mM} \mathrm{DPPH}$ in methanol was prepared, and $1.0 \mathrm{ml}$ of this solution was mixed with $3.0 \mathrm{ml}$ of extract in methanol containing 0.001-0.1 $\mathrm{mg} / \mathrm{ml}$ of the extract. The reaction mixture was vortexed thoroughly and left in the dark at room temperature for 30 minutes. The absorbance of the mixture was measured at $517 \mathrm{~nm}$ using a visible spectrophotometer (spectrum lab 23A, china). Ascorbic acid was used as a reference standard. The ability to scavenge DPPH radical was calculated by the following equation:

DPPH radical scavenging activity $(\%)=\left\{\left[\mathrm{A}_{0^{-}}\right.\right.$ $\left.\left.\mathrm{A}_{1}\right] / \mathrm{A}_{0}\right\} \times 100$

Where;

$\mathrm{A}_{0}$ is the absorbance of DPPH radical in methanol

$\mathrm{A}_{1}$ is the absorbance of DPPH radical + sample extract/standard in methanol.

The $50 \%$ inhibitory concentration value $\left(\mathrm{IC}_{50}\right)$ was determined by an exponential equation to match data into the concentration-response.

Determination of total phenolic content

The total phenolic content of the extract and fractions were determined according to the method previously described by Ebrahimzadeh et al. [12]. The extract solution $(0.5 \mathrm{ml})$ with a concentration of $1 \mathrm{mg} / \mathrm{ml}$ was added to $4.5 \mathrm{ml}$ of deionized distilled water and $0.5 \mathrm{ml}$ of Folinciocalteu's reagent (previously diluted with water 1:10, v/v). After mixing, the tubes were then allowed to stand at room temperature for 5 minutes and thereafter $5 \mathrm{ml}$ of $7 \%$ sodium carbonate and $2 \mathrm{ml}$ of deionized distilled water were added. The mixtures were afterwards incubated for 90 minutes at room temperature. The absorbance of each was measured at $750 \mathrm{~nm}$ using a spectrophotometer. The standard curve was prepared using gallic acid at concentrations of $12.5,25,50$, 75,100 , and $150 \mu \mathrm{g} \mathrm{ml}^{-1}$. The total phenolic content was expressed as milligrams of gallic acid equivalents (GAE) per gram of extract (mg GAE/g extract).

\section{Determination of total flavonoid content}

The total flavonoid contents of extracts and fractions were determined according to the method described by Siddique et al. [13]. The extract solution $(0.5 \mathrm{ml})$ of concentration $1 \mathrm{mg} / \mathrm{ml}$ was mixed with $1.5 \mathrm{ml}$ of methanol, $0.1 \mathrm{ml}$ of $10 \%$ aluminium chloride, $0.1 \mathrm{ml}$ of $1 \mathrm{M}$ potassium acetate and $2.8 \mathrm{ml}$ of distilled water. The mixture was left to stand at room temperature for 30 minutes. The absorbance was thereafter measured at $415 \mathrm{~nm}$ using a spectrometer. The standard curve was prepared using quercetin at concentrations of $12.5,25,50,75,100 \mu \mathrm{g} \mathrm{ml}^{-} 1$. The total flavonoid content was expressed as milligrams quercetin equivalents $(\mathrm{QE})$ per gram of extract $(\mathrm{mg}$ QE/g extract)

\section{Statistical analysis}

The statistical significance between antioxidant activity values of the extracts was evaluated by analysis of variance (ANOVA) followed by Dunnett's test. $P$ values less than 0.05 were considered to be statistically significant [14]. The experiments were carried out in triplicates unless otherwise specified. The test was carried out for statistical analysis and results are presented as mean \pm standard error of the mean (Mean \pm SEM).

\section{RESULTS AND DISCUSSION}

The results of the vacuum liquid chromatography revealed that 50\% ethyl acetate: 50\%methanol had the highest percentage yield of 51.25 which indicates that the bulk of the phytochemicals present in the extract are moderately polar. The result is given in Table 1 
Table 1. Percentage yield of crude extract and fractions of $C$. pulcherrima leaf

\begin{tabular}{ll}
\hline Samples & Percentage yield (\%) \\
\hline Crude & 20.77 \\
$100 \%$ n-hexane & 0.90 \\
$50 \%$-hexane:50\% ethyl acetate & 9.33 \\
$100 \%$ ethyl acetate & 5.57 \\
$50 \%$ ethyl acetate: $50 \%$ methanol & 51.25 \\
$100 \%$ methanol & 5.80 \\
$90 \%$ methanol:10\% water & 7.27 \\
\hline
\end{tabular}

1,1-diphenyl-2-picrylhydrazyl (DPPH) is a nitrogen centred stable free radical having a maximum absorption at $517 \mathrm{~nm}$ in alcoholic solution [15]. It becomes a stable diamagnetic molecule on accepting an electron or hydrogen atom. In the presence of an extract capable of donating a hydrogen atom, the free radical nature of the DPPH is lost and the purple colour changes to yellow $[16,17]$. The bleaching of DPPH radical is one of the most widely used strategies to evaluate the antioxidant activity of herbal extracts. This method is simple, rapid and measures the capacity of herbal extract to bleach the DPPH radical. The method is sensitive and requires a small number of samples [17]. DPPH free radical scavenging activity of $C$. pulcherrima leaf extract and fractions showed an appreciable and dosedependent increase in scavenging effect from $25 \mu \mathrm{g} / \mathrm{ml}$ to $100 \mu \mathrm{g} / \mathrm{ml}$ for the standard (ascorbic

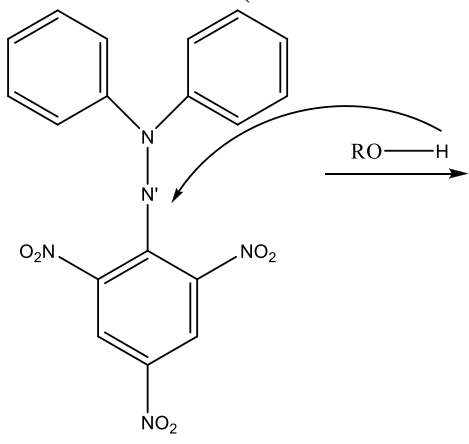

acid), crude and some of the fractions (Table 2). At the highest concentration $(200 \mu \mathrm{g} / \mathrm{ml})$, the percentage inhibition of the crude extract_and fractions ranged from $35.67 \pm 9.77 \%$ to $98.77 \pm 0.09 \%$, whereas, the reference standard had a percentage inhibition of $99.14 \pm 0.28 \%$ (Table 2). The $\mathrm{IC}_{50}$ value is the concentration that will inhibit $50 \%$ of the initial DPPH radical [17]. Examination of the crude extract along with fractions as shown in Table 3 demonstrated that the ethyl acetate fraction exhibited the highest antioxidant activity, with $\mathrm{IC}_{50}$ of 9.15 $\mu \mathrm{g} / \mathrm{ml}$. These results supported the findings of Junaid et al [15]. The $\mathrm{IC}_{50}$ of the ethyl acetate fraction was relatively low when compared to others; however, it was significantly different $(\mathrm{p}<0.01)$ from that of the reference standard $(3.20$ $\mu \mathrm{g} / \mathrm{ml}$ ).

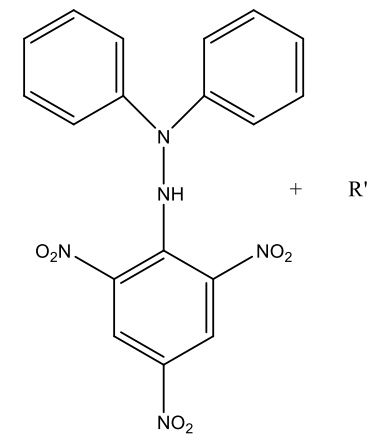

Scheme 1: The reaction of DPPH with antioxidant compound ROH 
Table 2: DPPH-scavenging activity of crude extract and fractions of $C$. pulcherrima

\begin{tabular}{ccccccccc}
\hline $\begin{array}{c}\text { Conc } \\
(\mu \mathrm{g} / \mathrm{ml} \\
)\end{array}$ & $\begin{array}{c}\text { Ascorbic } \\
\text { acid }(\%)\end{array}$ & Crude $(\%)$ & $\begin{array}{c}100 \% \\
\text { n-hexane }(\%)\end{array}$ & $\begin{array}{c}50 \% \\
\text { n-hexane: } 50 \% \\
\text { ethyl acetate } \\
(\%)\end{array}$ & $\begin{array}{c}100 \% \\
\text { ethyl acetate } \\
(\%)\end{array}$ & $\begin{array}{c}50 \% \text { ethyl } \\
\text { acetate } \\
50 \% \text { methanol } \\
(\%)\end{array}$ & $\begin{array}{c}100 \% \\
\text { methanol }(\%)\end{array}$ & $\begin{array}{c}90 \% \text { methanol } 10 \% \\
\text { water }(\%)\end{array}$ \\
\hline 1 & $32.99 \pm 5.88$ & $9.43 \pm 3.99$ & $26.63 \pm 9.39$ & $38.02 \pm 6.63$ & $25.46 \pm 4.11$ & $23.61 \pm 1.02$ & $52.09 \pm 1.04$ & $5.69 \pm 1.03$ \\
2 & $39.63 \pm 9.77$ & $16.20 \pm 3.67$ & $34.17 \pm 3.82$ & $41.53 \pm 3.63$ & $16.24 \pm 2.85$ & $23.62 \pm 1.71$ & $27.47 \pm 3.30$ & $5.02 \pm 3.38$ \\
5 & $90.57 \pm 3.22$ & $16.87 \pm 3.04$ & $62.46 \pm 3.10$ & $36.85 \pm 6.36$ & $54.27 \pm 4.50$ & $35.34 \pm 1.08$ & $40.03 \pm 7.74$ & $11.39 \pm 2.26$ \\
10 & $95.63 \pm 0.33$ & $25.22 \pm 3.54$ & $23.61 \pm 6.96$ & $33.66 \pm 7.22$ & $98.80 \pm 0.28$ & $61.80 \pm 4.80$ & $53.76 \pm 3.70$ & $5.52 \pm 2.33$ \\
25 & $98.58 \pm 0.79$ & $46.56 \pm 2.01$ & $21.44 \pm 1.14$ & $48.74 \pm 3.67$ & $94.97 \pm 0.67$ & $96.98 \pm 2.22$ & $89.60 \pm 4.28$ & $4.18 \pm 1.09$ \\
50 & $98.99 \pm 0.25$ & $73.86 \pm 1.42$ & $38.19 \pm 3.34$ & $72.52 \pm 8.53$ & $97.98 \pm 0.50$ & $94.97 \pm 1.84$ & $69.17 \pm 5.78$ & $18.25 \pm 1.34$ \\
100 & $99.53 \pm 1.02$ & $93.29 \pm 1.46$ & $58.96 \pm 7.75$ & $97.15 \pm 0.58$ & $98.47 \pm 0.42$ & $94.97 \pm 0.50$ & $95.30 \pm 1.69$ & $6.34 \pm 1.31$ \\
200 & $99.14 \pm 0.28$ & $89.94 \pm 1.97$ & $59.96 \pm 6.34$ & $90.28 \pm 0.67$ & $98.77 \pm 0.09$ & $97.82 \pm 0.53$ & $97.98 \pm 1.40$ & $35.67 \pm 9.77$ \\
\hline
\end{tabular}

Data represent mean \pm Standard error of the mean of triplicate analysis

Table 3. $\mathrm{IC}_{50}$ values of extract and fractions of $C$. pulcherrima leaf and the reference standard (ascorbic acid)

\begin{tabular}{lc}
\hline Sample & $\mathrm{IC}_{50}(\mu \mathrm{g} / \mathrm{ml})$ \\
\hline Ascorbic acid & $3.20^{\mathrm{a}}$ \\
$100 \%$ n-hexane & $48.11^{\mathrm{b}}$ \\
50 n-hexane/50\% ethyl acetate & $33.12^{\mathrm{c}}$ \\
$100 \%$ ethyl acetate & $9.15^{\mathrm{d}}$ \\
$50 \%$ ethylacetate $/ 50 \%$ methanol & $27.26^{\mathrm{e}}$ \\
$100 \%$ methanol & $17.90^{\mathrm{f}}$ \\
$90 \%$ methanol/10\% water & $272.18^{\mathrm{g}}$ \\
Crude & $55.51^{\mathrm{h}}$ \\
\hline
\end{tabular}

Values with different superscripts are significantly different $(\mathrm{p}<0.05)$.

contents indicated that the $100 \%$ methanol fraction

Table 4 shows the total phenol and total flavonoid contents of $C$. pulcherrima leaf extracts and fractions. The total phenol content were reported as

$\mathrm{mg}$ gallic acid equivalent/g of extract, by reference to a standard curve $\quad\left(\mathrm{y}=0.002 \mathrm{x}+0.051 ; \mathrm{R}^{2}\right.$ $=0.956)$. The total flavonoid content was reported as mg quercetin equivalent/g of extract by reference to a standard curve $\left(y=0.002 x+0.194, R^{2}=0.989\right)$. Fractionation of the leaf extract shows that the total phenolic and flavonoid contents were significantly $(\mathrm{p}<0.05)$ higher in the ethyl acetate fraction than other fractions (Table 4). The results clearly show that solvent extraction influences the extractability of the phenolic and flavonoid compounds in plants. The result of the total phenolic and total flavonoid contained a significantly $(\mathrm{p}<0.05)$ lesser amount of phenol $(5.50 \pm 0.01)$ and a moderate amount of flavonoids (77.0 \pm 0.02$)$. Hence the antioxidant activity reported in this study may also be due to the

phenolic and flavonoid content of the plant, this is because the presence of hydroxyl $(\mathrm{OH})$ groups in the phenolic and flavonoid compounds may directly contribute to their radical scavenging ability. However, the antioxidant activities are more likely to be influenced by the flavonoids compared to the phenolics (Table 4). On the other hand, the total phenolic and flavonoid contents reported in this work are significantly higher than the results obtained by Junaid et al [15]. This, therefore, indicates that $C$. pulcherrima could be a very promising source of phenolic and flavonoid compounds. 
Table 4.Total phenol and total flavonoid contents of extract and fractions of $C$. pulcherrima leaves.

\begin{tabular}{lll}
\hline Fractions of the extract & $\begin{array}{l}\text { Total phenol } \\
(\mathrm{mg} \mathrm{GAE} / \mathrm{g} \text { extract })\end{array}$ & $\begin{array}{c}\text { Total flavonoid } \\
\text { (mg QE/g extract) }\end{array}$ \\
\hline n-hexane;100\% & $10.50 \pm 0.01^{\mathrm{a}}$ & $93.00 \pm 0.00^{\mathrm{a}}$ \\
n-hexane;50\%.ethyl acetate;50\% & $64.50 \pm 0.02^{\mathrm{d}}$ & $393.00 \pm 0.02^{\mathrm{b}}$ \\
ethyl.acetate;100\% & $149.50 \pm 0.01^{\mathrm{b}}$ & $658.00 \pm 0.02^{\mathrm{c}}$ \\
ethyl acetate ;50\%.methanol;50\% & $118.00 \pm 0.04^{\mathrm{c}}$ & $23.00 \pm 0.02^{\mathrm{d}}$ \\
methanol.100\% & $5.50 \pm 0.01^{\mathrm{e}}$ & $77.00 \pm 0.02^{\mathrm{e}}$ \\
methanol; 90\%.water;10\% & $15.50 \pm 0.00^{\mathrm{f}}$ & $92.00 \pm 0.00^{\mathrm{a}}$ \\
Crude & $4.50 \pm 0.00^{\mathrm{ge}}$ & $93.00 \pm 0.00^{\mathrm{a}}$ \\
\hline
\end{tabular}

Values are represented as Mean \pm SEM for three determinations.

Means with different superscripts are significantly different $(\mathrm{p}<0.05)$.

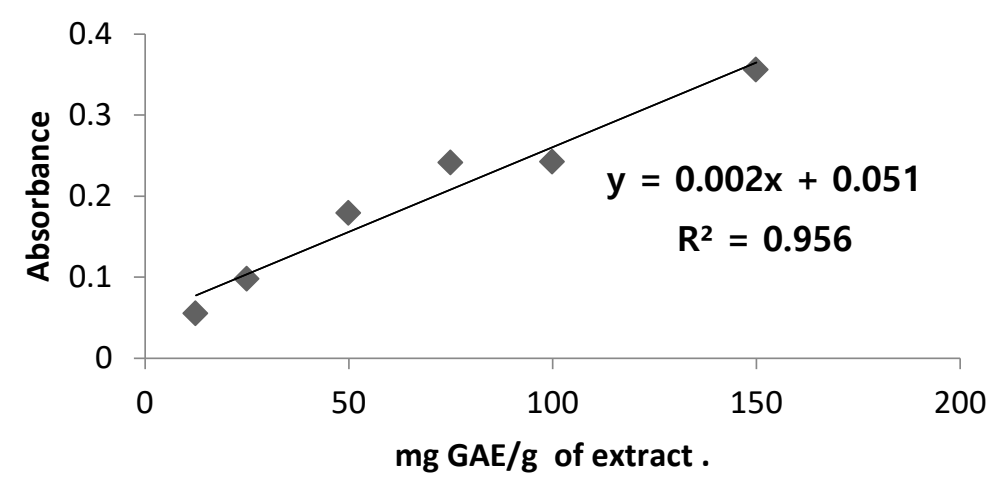

Fig. 1: Gallic acid standard curve

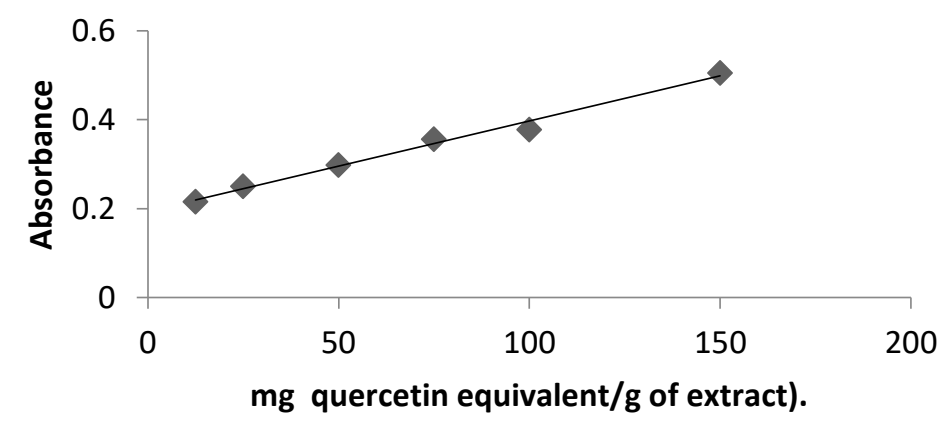

Fig. 2 Quercetin curve

\section{CONCLUSION}

The result of the present study revealed that the leaf extract and fractions of $C$. pulcherrima have an appropriate amount of flavonoid and phenolic compounds which may be the key determinant of their antioxidant activity. These findings demonstrate that $C$. pulcherrima leaf may be a good candidate from which specific bioactive products could be developed.

\section{REFERENCES}

1. L.A. Mitscher, Y.H.Parkand D. Clark (1980).Antimicrobial agents from higher plants, antimicrobial isoflavonoid and related substance 
from glycyrhizaglabra, journal of Natural products, 43259-304

2. R.K.Monin and V.B. Kadam(2012). Determination of soluble extractive of some medicinal plants of genus sesbania of Marathwada region in Maharashtra. International journal of life science and pharma research, $2: 2$

3. A. Falodun, O. Erharuyi and C.N, Akunyili (2015).Nigerian Journal of Applied Science, 33:49

4. M. Valko, C.J. Rhodes, J.Mancol, M. Izakovic andM. Mazur(2006).Free radicals, metals and antioxidants in oxidative stress-induced cancer. Chem Bio inter, 16:1-40

5. L. Bergendi, L. Benes,Z. Durackova and M. Ferencik(1999). Chemistry, physiology and pathology of free radicals. Life science, 65: 18651874

6. K.J.A. Davies(1995). Oxidative stress; the paradox of aerobic life. Biochem. Soc. Sym, 61 (1) 1-34

7. D.M.Miller,G.R. Buetner and S.D.Aust(1990). Transition metals as catalysts of Autoxidation reactions of Free radicals, bio. Med8 95-108.

8. P. Kovacicand J.D. Jacintho(2001).Mechanism of carcinogenesis Focus on oxidative stress and electron transfer. Current Med. Chem, 8 773-796

9. M.A.Jayasri, L. Mathew andA. Radha(2009).A report on the antioxidant activities of leaves and rhizomes of costuspictus D. Don international journal pf integrative biology,5(1):20-26

10. O.K. Ogbeide, V.O. Dickson, R.D. Jebba, D.A. Owhiroro, M.O. Olaoluwa, V.O. Imieje, O. Erharuyi, B.J. Owolabi, P. Fasinu and A. Falodun (2018). Antiplasmodial and Acute Toxicity Studies of Fractions and Cassane-Type Diterpenoids from the Stem Bark of Caesalpinia pulcherrima (L.)
Sw. Tropical Journal of National Product Research; 2(4):179-184.

11. D.O. Kim,S.W. Jeong, and C.Y. Lee(2003).Antioxidant capacity of phenolic phytochemicals from various cultivars of plums. Food Chem,81:321-326

12. M.A. Ebrahimzadeh, F. Pourmorad and A.R.Bekhradnia(2008).Iron chelating activity, phenol and flavonoid content of some medicinal plant from Iran. Afr. J.Biotechnol, 7(18) 3188-3192

13. N. A. Siddique, M. Mujeeb, A.K. Najmiand M. Akram (2010). Evaluation of antioxidant activity, quantitative estimation of phenols and flavonoids in different parts of Aegle marmelos. African Journal of Plant Science,4 (1) 001-005

14. T. Kulisic, A. Radonic, V. Katalinic and M. Milos (2004). Use of different methods for testing antioxidative activity of oregano essential oil. Food Chemistry, 85: 633-640.

15. S. Junaid,KN. Rakesh, N.Dileep, G. Poornima, T.R.P.Kekuda, and S. Mukunda(2013).Total phenolic content and antioxidant activity of seed Extract of Lagerstroemia speciosaL. Chemical Science Transactions,2(1): 75-80.

16. M.N.Amin, S.M.R,Dewan, W. Noor, U.D Shahid and A.F.M Dauls (2013). Characterization chemical groups and determination of total phenolic content and in vitro antioxidants activities of the ethanolic extracts of Ocinumsantum leaves growing in Bangladesh. Euro J. Exp Bio,3(1): 449-454

17. C.A Unuigbe, H.A. Okeri, O. Erharuyiand E.EOghenero, (2014). Phytochemical and antioxidant evaluation of Moringaoleifera leaf and seed. Journal of Pharmacy and Bioresourses,11(2), $51-57$ 